\title{
La fiesta, żun espejo de la sociedad? Una aproximación a las celebraciones vinculadas a la producción económica local (Ayacucho 1969-1979)
}

\author{
The party, a mirror of society? An approximation to celebrations linked to local \\ economic production (Ayacucho 1969-1979)
}

\section{Silvana Villanueva \\ villanuevasilvana1@gmail.com \\ Centro Interdisciplinario de Estudios Politicos, \\ Sociales y Juridicos-Facultad de Ciencias Humanas- \\ Universidad Nacional del Centro de la Provincia de \\ Buenos Aires/CONICET, Argentina}

Recepción: 20 Marzo 2020

Aprobación: 08 Septiembre 2020

Publicación: 13 Noviembre 2020

Cita sugerida: Villanueva, S. (2020). La fiesta, ¿un espejo de la sociedad? Una aproximación a las celebraciones vinculadas a la producción económica local (Ayacucho 1969-1979). Anuario del Instituto de Historia Argentina, 20(2), e127. https://doi.org/10.24215/2314257Xe127
Resumen: Este artículo propone un abordaje, desde la disciplina histórica, de las fiestas vinculadas a la actividad económica local que emergieron a partir de la década del sesenta en la provincia de Buenos Aires. Entendemos que un análisis de las mismas a través del tiempo, contribuye a echar luz sobre los cambios que vivenciaron las sociedades del interior rural bonaerense hacia fines del siglo XX. Para ello, haremos una aproximación a la primera década de celebración de la Fiesta Nacional del Ternero y Día de la Yerra, que se celebra en el partido de Ayacucho desde 1969. A través del análisis del programa oficial de festejos, buscamos dar cuenta de las continuidades y permanencias que se registraron en el evento durante sus primeros años de celebración, entendiendo que, pueden ser representativas de las transformaciones que afectaron a la sociedad que celebraba.

Palabras clave: Fiesta, Sociedad, Rural.

Abstract: This article proposes an approach, from the historical discipline, to the festivals linked to local economic activity that emerged from the sixties in the province of Buenos Aires. We understand that an analysis of them over time contributes to shedding light on the changes experienced by societies in rural Buenos Aires towards the end of the 20th century. To do this, we will make an approach to the first decade of celebration of the National Calf Festival and Yerra Day, which has been celebrated in the Ayacucho district since 1969. Through the analysis of the official festival program, we seek to account for the continuities and permanence that were registered in the event during its first years of celebration, understanding that they may be representative of the transformations that affected the society that was celebrating.

Keywords: Rural, Society, Feast. 


\section{INTRODUCCIÓN}

"Es esta la verdadera fiesta de un pueblo, puesto que de su seno nace la iniciativa de solicitarla y es él mismo, quien asume el máximo compromiso de llevarla a cabo". ${ }^{1}$ Así caracterizaba el origen de la Fiesta Nacional del Ternero y Día de la Yerra, el comisionado municipal del partido de Ayacucho, Guillermo Schoo Lastra, quien había sido uno de los principales gestores de la institucionalización de dicha fiesta. Los orígenes de la misma se remontan a la celebración de una yerra en la estancia San Bernardo (ubicada a pocos kilómetros de la ciudad), en la cual un grupo de participantes enarboló la idea de acercar esa fiesta a la comunidad. Desde ese momento se iniciaron las gestiones que dieron entidad a la misma. La conclusión de la iniciativa se materializó en el decreto nacional de 1968 firmado por el presidente de facto Juan Carlos Onganía y su ministro de Economía Adalbert Krieger Vasena. Dicho documento en sus argumentos enfatizaba la labor del hombre de campo, la importancia de Ayacucho como productor ganadero, y de la yerra como una de las prácticas criollas que "forman parte del acervo espiritual de nuestra raza". 2

¿Constituyen las fiestas un reflejo de lo que acontece en la sociedad? ¿Son representativas de los valores y las tensiones que atraviesan a las sociedades? ¿Cuál es el sentido de celebrar? ¿Quiénes celebran? Estos son algunos de los interrogantes que desde las ciencias sociales han ido trazando el camino del estudio sobre la fiesta. Mona Ozouf considera que son las fiestas las que

articulan el tiempo y dan a la vida su armazón. Son también las fiestas las que, paradójicamente, garantizan las buenas costumbres; porque el exceso que permiten es el mal menor que impide que el desenfreno se adueñe de la vida cotidiana y de todo el cuerpo social; las que, de manera enérgica, dan cimiento a la comunidad con la puesta en escena de la reconciliación, con esa calidad comensalidad en el que todo tiene un valor (Ozouf, 2020, p. 13).

Es así que la disciplina histórica ha ido posando su atención en la fiesta como acontecimiento histórico revelador de las rupturas y continuidades que atraviesan a las sociedades en diferentes momentos de su historia. En este sentido, como afirma Roger Chartier, más allá de sus atributos pintorescos, la fiesta se ha convertido "en gran reveladora de las compartimentaciones, tensiones y representaciones que atraviesan una sociedad" (Chartier, 2005, p. 20). En la historiografía argentina, historiadoras e historiadores como Garavaglia (1997) (2007), Salvatore (1996), Navarro (2011), Munilla Lacasa (2013), Ortemberg (2009), entre otros, elevaron a la fiesta como objeto de investigación, y, a través de su estudio, han enriquecido sus perspectivas de análisis sobre las sociedades que indagan.

En este trabajo centraremos nuestra mirada en las celebraciones vinculadas a la actividad económica local, o cuyo objeto de celebración era la conmemoración de prácticas propias del mundo rural. A lo largo del siglo $\mathrm{XX}$, estas fiestas se fueron convirtiendo en parte de la cotidianeidad de muchas comunidades del interior argentino. Las mismas se instauraron, junto a las fiestas religiosas y a las fiestas cívicas, como los eventos más distintivos de estas sociedades, y se consolidaron como bastión de la expresión de las tradiciones locales. Las tensiones en torno a las representaciones sobre dichas tradiciones, y las continuidades y transformaciones que sufrieron estas celebraciones en sus diferentes ediciones, establecen el punto de partida de nuestro interés analítico por este tipo de evento, ya que, entendemos, pueden arrojar luz sobre la configuración que fueron adquiriendo las sociedades que celebran en distintos momentos de su historia.

En el caso de la provincia de Buenos Aires, la multiplicación de celebraciones vinculadas a homenajear la labor rural y la economía local coincide con el inicio de una serie de importantes trasformaciones (cambios en la estructura productiva, en la distribución de la población, entre otros), que afectaron a la producción agropecuaria hacia fines de la década del sesenta y que tendieron a profundizarse en las décadas siguientes (Barsky y Gelman, 2009; Balsa, 2014). Como consecuencia de estos cambios, el lugar preponderante que el mundo rural había ocupado en el desarrollo económico y social de los distintos partidos que se erigieron en torno a la expansión agropecuaria sufrió importantes alteraciones. 
Para avanzar en esta hipótesis realizaremos una aproximación a la primera década de celebración de la Fiesta Nacional del Ternero y Día de la Yerra, que se realiza desde 1969 en el partido de Ayacucho (en el sudeste de la provincia de Buenos Aires). Desde su fundación en el siglo XIX, la actividad ganadera, ovina y vacuna fue modelando a esta localidad, que forma parte de la región atravesada por la depresión del río Salado.

Entendemos que, una primera aproximación al desarrollo de esta celebración, puede contribuir a enriquecer posibles investigaciones en períodos más amplios, y extenderse a su vez a otras celebraciones, para dar cuenta de la dinámica que atravesaron y atraviesan a estos eventos, así como también, mediante ello, se podrían explorar las transformaciones que sufre el tejido social de estas comunidades en relación con los cambios que se sucedían en la esfera nacional y provincial.

Por otra parte, la elección de esta fiesta y de su primera década de celebración (además de que ya ha sido abordada en sus orígenes en otros trabajos) obedece a que es una de las primeras celebraciones que emergen a fines de la década del sesenta en la provincia de Buenos Aires y que adquiere carácter nacional en dicho período. A su vez, contribuye a nuestra selección el hecho de que el partido de Ayacucho había sido caracterizado, por el gobierno de facto del Gral. Juan Carlos Onganía, como la "capital nacional del ternero", debido a la cantidad de cabezas de ganado vacuno existente en el mismo hacia fines de la década del sesenta. A lo largo de la década del setenta, la situación de la actividad ganadera sufrió importantes modificaciones ocasionadas por los vaivenes de las políticas gubernamentales, los cambios en las formas de producir que acontecieron en el sector agropecuario, así como por las contingencias del mercado internacional de la carne.

A continuación haremos un breve recorrido por algunas de las principales transformaciones que se avecinan en dicho período y que afectan particularmente al agro pampeano. Luego, iniciaremos nuestro análisis de los primeros diez años de celebración de la Fiesta Nacional del Ternero y Día de la Yerra, contextualizándola en el marco de emergencia de otras celebraciones. Para ello, trabajaremos en torno al Programa Oficial de Festejos, ${ }^{3}$ ideado por la comisión organizadora, el cual a nuestro entender da cuenta de la significación que la fiesta tenía para quienes la organizaban. Pero, además, creemos que es posible identificar mediante los cambios y continuidades que se visualizan en dicho programa, el sentido que la comunidad fue otorgando a la celebración a lo largo del período estudiado. A través de esto, podremos avanzar en los cambios culturales, políticos, económicos y sociales que se vivenciaron en la comunidad que celebraba. Para enriquecer nuestro análisis, recurrimos a la cobertura que tanto la prensa local como la nacional hizo del evento, así como a los discursos que pronunciaron las autoridades gubernamentales (nacionales, provinciales y locales) y a la nómina de referentes del sector agropecuario que asistieron a la celebración.

\section{El AGRo EN LA DÉCADA DEL SETENTA}

Los primeros diez años de celebración de la Fiesta Nacional del Ternero Y Día de la Yerra coinciden con la continuidad de un período de inestabilidad institucional marcado por un breve retorno al régimen democrático, el regreso a la presidencia de Juan Domingo Perón, y con el inicio de la ltima y más violenta (entendida en términos de ejercicio de la represión estatal) dictadura militar argentina. En paralelo, la economía no estuvo exenta de los vaivenes que caracterizaron al universo político del momento, los cuales afectaron las proyecciones sobre el rol, interventor o no, del Estado en la elaboración de políticas para los distintos sectores de la economía.

La política agropecuaria y los debates en torno a la misma adquirieron relevancia en este período. "Fue ganando lugar dentro del sector (agropecuario) un discurso que exigía un tipo de cambio más elevado, una reducción de los impuestos y gravámenes a las exportaciones" (Aronskind, 2007, p. 70). Este discurso fue adquiriendo un lenguaje antiestatista, que impregnó las disputas del sector en los diferentes gobiernos durante las décadas del setenta y ochenta, y que, como se verá a continuación, se hicieron evidentes en el pequeño universo de la fiesta aquí estudiada. 
La década del sesenta concluye con el fin de la prórroga a los contratos de arrendamientos, que desde 1942 regulaba la tenencia de la tierra, lo que implico el descongelamiento de los mismos. Esta situación marcó un proceso de transformación importante en la tenencia de la tierra a lo largo de los años setenta, en tanto que algunos arrendatarios accedieron a la propiedad de la tierra, otros se vieron obligados a abandonarlas. También las condiciones de producción se modificaron drásticamente, situación que repercutió en el destino de muchos productores. En este sentido, Balsa sostiene que los factores que contribuyeron a modificar la estructura social del agro fueron varios. En principio, señala que

los requerimientos de capital y extensión de las explotaciones para un completo aprovechamiento de las innovaciones tecnológicas habrían hecho muy difícil la situación a los pequeños productores agropecuarios. En segundo término, el contexto económico de alta inflación, caída de los precios ganaderos y altas tasas de interés, también habría jugado en contra de la estabilidad de estos productores. Finalmente, este cuadro se vio agravado por el retroceso del Estado en su papel de promotor de inversiones y apoyo a los pequeños productores, y por las políticas cambiarias e impositivas (Balsa, 2006, p. 139).

En las décadas del setenta y del ochenta se registra un avance de la agricultura por sobre la actividad ganadera (Balsa, 2014, p. 168), inclusive con la incorporación de pasturas para alimentar a las cabezas de ganado.

Particular debate suscitó en este período el proyecto de ley que sancionaba un impuesto a la Renta Normal Potencial de la Tierra, ideado por Horacio Giberti, quien ocupó la Secretaria de Agricultura y Ganadería en 1973. "El impuesto, que gravaba con una suma fija el suelo, independientemente de su producción, se suponía que impulsaría a evitar la tenencia de tierra ociosa o en condiciones de baja productividad en relación con sus condiciones naturales" (Barsky y Gelman, 2001, p. 361). Luego de su aprobación por el Parlamento, el impuesto fue muy difícil de aplicar, debido, fundamentalmente, a la conflictividad social, la inestabilidad del gobierno y el rechazo cada vez mayor de parte de las entidades representantes del sector agropecuario, por lo que la ley fue derogada en septiembre de 1976 (Brasky y Gelman, 2001) (Balsa, 2014).

No solo las cargas impositivas y las demandas de incorporación de nuevas tecnologías modelaron las características del sector agropecuario. También lo hicieron las limitaciones comerciales internacionales. A las sucesivas vedas de comercialización interna de la carne de principios de la década se le agregó, en 1974, una nueva restricción del Mercado Común Europeo, que impedía el ingreso de carne vacuna debido a la existencia de aftosa, situación que repercutió en la actividad ganadera (Aronskind, 2007, p. 83).

En mayo de 1974, en el marco de la reunión de las sociedades rurales de La Pampa, Jorge Aguado, quien en ese entonces era presidente de la Comisión de Enlace de estas entidades, sintetizó como "una política anti campo" las medidas antes mencionadas. En la misma incluía a "los precios políticos, impuestos exorbitantes, amenaza a la propiedad y a la libre disponibilidad de las explotaciones, al intervencionismo estatal, y la incongruente conducción económica en el área rural". Consideraba, además, que "este cúmulo de circunstancias negativas está sumiendo a la producción del campo en un abismo de inquietudes desalentadoras por mucho que pueda no ser esa la intención oficial" (La Nación, 5 de mayo de 1974).

La liberalización generalizada de los mercados junto a la apertura económica al exterior caracterizaron la política económica de la dictadura militar establecida en marzo de 1976 (Barsky y Gelman, 2001). La reforma financiera y del Estado llevada adelante en esos años contribuyó a desmantelar muchos organismos e instituciones que accionaban y regulaban el sector agropecuario. Las entidades representantes de sector agropecuario acompañaron el proyecto de la dictadura, e incluso algunos de sus representantes pasaron a ser funcionarios del gobierno.

"Desde la presidencia de CARBAP, Jorge Aguado se manifestó en favor del proyecto de la dictadura, aunque cuestionaba ciertas políticas" (Balsa, 2014, p. 167). Más adelante, en 1981, este referente del agro pasó a convertirse en funcionario del gobierno militar, como ministro de Agricultura y Ganadería de la Nación, para luego pasar a ejercer como gobernador de la provincia de Buenos Aires.

Los acontecimientos antes mencionados tuvieron sobre el territorio bonaerense amplias repercusiones, fundamentalmente en aquellos partidos en los que, como en Ayacucho, la actividad agropecuaria seguía 
teniendo un rol preponderante en la actividad económica local. En cuanto a la tenencia de la tierra, según datos arrojados por el censo agropecuario de 1960 y el de 1988, en ese período se registra una disminución de la cantidad de explotaciones, así como una tendencia hacia la concentración de la tierra en explotaciones mayores a 400 hectáreas. Por otra parte, en el mismo lapso de tiempo hay una disminución de la población rural, que tiende a profundizarse en las décadas siguientes. ${ }^{4}$ No solo la desaparición de propiedades pequeñas aceleró este proceso migratorio, sino también la incorporación de nuevas técnicas, la injerencia de trabajo asalariado, así como el acceso a mejores condiciones de vida (en términos de educación, empleo y salud) que se desplegaban en la ciudad.

\section{Celebrar la economía local}

Es en este contexto en el que empiezan a aparecer en la provincia de Buenos Aires las fiestas vinculadas a la celebración de algún elemento característico de la economía local o identificada con las prácticas rurales. La Fiesta Nacional del Ternero y Día de la Yerra en Ayacucho (1969), la Fiesta Provincial del Trigo en Tres Arroyos (1970), la Fiesta Nacional del Maíz en Chacabuco (1970), la Fiesta Nacional de la Flor en Escobar (1968), la Fiesta Nacional del Ave de Raza (1975) fueron, entre otras, las principales fiestas que irrumpieron en este período en la provincia de Buenos Aires. Otras fiestas, como la actual Fiesta Provincial de la Papa en Otamendi o la Fiesta Nacional del Girasol en Carlos Casares, se originaron en la década del sesenta pero tenían un alcance regional. Una aproximación a la esencia de este tipo de eventos nos propone el antropólogo Hugo Ratier (2004), quien afirma:

Hay un recurso de supervivencia que apela dramáticamente a la reafirmación identitaria. Central en estas celebraciones es la actividad criollista, los desfiles y jineteadas, la comida típica centralizada en el proverbial asado. Funciona aquí un circuito redistributivo corporizado en la donación de vaquillonas por los estancieros, materia prima transformada por la vaquía de los asadores vernáculos que en la alta madrugada lidian con el fuego y los costillares, o con la vaca con cuero de importancia quizás más ritual que alimenticia, toda una prueba de fuerza para quienes la preparan. Esos servicios suelen no pagarse en dinero, sino con el acceso libre a la comida (Ratier, 2012, p. 120).

En su mayoría, los orígenes de estas celebraciones respondieron a la iniciativa de un grupo de productores vinculados a la actividad agropecuaria, que, tras las gestiones con los gobiernos locales, terminaron por dar forma a la celebración.

En el caso de la fiesta aquí estudiada, su origen se remonta al año 1967, cuando, en el marco de la celebración de una yerra en la estancia San Bernardo, ${ }^{5}$ se forjó la idea de que Ayacucho reivindicara la labor del hombre de campo a partir de la creación de una fiesta dedicada al ternero y a la yerra. Durante dicho evento, los asistentes (productores ganaderos, empresarios, figuras públicas, vecinos del sector rural del partido de Ayacucho) firmaron un petitorio dirigido al intendente (comisionado en ese entonces y participante de esa celebración de la yerra). La máxima autoridad municipal fue quien inició la gestión por la institucionalización de la fiesta. Luego del decreto nacional que le dio entidad a la celebración se procedió a la constitución de una comisión ejecutora, que a partir de la cuarta edición dio paso a la emergencia de una asociación civil, que se encarga, desde ese entonces, de organizar la celebración. En líneas generales, los integrantes de la primera comisión resultaron ser partícipes de aquella yerra en la estancia San Bernardo; estaban vinculados a la actividad agropecuaria en su mayoría y eran referentes de actividades de la ciudad, como el cura párroco o funcionarios públicos (Villanueva, 2014).

Pero las celebraciones vinculadas a la economía local tienen precedentes más lejanos en el tiempo a nivel nacional.

La Fiesta de la Vendimia, no solo fue una de las pioneras en celebrar la producción económica local en el territorio argentino, sino también en lograr su institucionalización a través de un decreto provincial en 1936 (Chamosa, 2012). No obstante, la expansión de este tipo de celebraciones y su institucionalización 
por parte del Estado alcanzaron mayor relevancia en la década siguiente. Oscar Chamosa (2012) afirma que la proliferación de estas fiestas en el territorio nacional coincide con la administración del primer gobierno peronista. A fines de la década del cuarenta se crean e institucionalizan celebraciones como la Fiesta Nacional del Algodón en Chaco, la Fiesta Nacional de la Zafra en Tucumán, así como otras fiestas provinciales que luego adquirirían carácter nacional, como la Fiesta de la Yerba Mate en Apóstoles (Misiones), la Fiesta del Trigo en Leones (Córdoba) o la Fiesta de los Pescadores en Mar del Plata (Buenos Aires). Al mismo tiempo en que se institucionalizaron nuevas fiestas se modificaron las representaciones sobre los objetos e inclusive los actores que eran considerados como ejes de la celebración. Al entender de Chamosa,

Mientras en el período pre peronista se celebraba la industria regional (y por ende a los capitalistas que la explotaban), en el período peronista se pasó a celebrar por un lado al trabajador, sea cosechero, zafranero o yerbatero, en su condición de descamisado, y por otro, a Perón mismo, su héroe liberador (Chamosa, 2012, p. 126).

Lejos de constituir eventos aislados de la dinámica social, las fiestas estaban impregnadas de las tensiones que en esas sociedades existían. A partir de mediados de siglo, se observa una mayor injerencia en la regularización estatal (ya sea del Estado nacional, provincial o municipal) en este tipo de celebraciones. La misma se da a través de la sanción de decretos, ordenanzas e inclusive en la participación de las diversas gestiones gubernamentales en la organización del evento. Es posible dilucidar que no todos los gobiernos perseguían los mismos objetivos a la hora de dar cauce a estas celebraciones, ni significaban de igual manera aquellos objetos que eran celebrados.

En las décadas siguientes, estas fiestas continuaron expandiéndose. A principios de los sesenta, los festivales folclóricos también ganaron espacio dentro del abanico de celebraciones que emergieron en el territorio nacional.

La mayor parte de las celebraciones vinculadas a enaltecer algún elemento o práctica de tradición rural se siguen realizando y muchas de ellas se aproximan o han superado sus cincuenta ediciones. Entendemos que, si profundizamos desde una perspectiva histórica en el estudio de las mismas, podemos llegar a vislumbrar aquellas características que las dotaron de singularidad y los distintos intereses que fueron modelándolas desde sus orígenes, lo que enriquece nuestra perspectiva sobre las transformaciones que sufrió la sociedad que celebra, sobre sus valores, representaciones, costumbres, instituciones, la construcción de su identidad y otros elementos que interactuaron para darle forma.

En este sentido, consideramos que, al interés analítico sobre las intencionalidades seguidas por los distintos gobiernos a la hora de instaurar y contribuir a la expansión de este tipo de fiestas, es necesario incorporar una mirada que se aproxime a los intereses perseguidos por los actores locales, las motivaciones de los propios participantes en formar parte de la celebración y ahondar en las significaciones que ellos le otorgaron a la fiesta en distintos momentos.

A continuación, con el objeto de contribuir en esta línea de análisis a futuras investigaciones, haremos un recorrido por las características que asumió la Fiesta Nacional del Ternero y Día de la Yerra durante su primera década de celebración. Pondremos énfasis en aquellos elementos que manifiestan continuidad con su primera edición y en aquellos que nos permiten visualizar transformaciones en la forma de celebrar. Para ello, nos centraremos en el análisis comparativo del programa oficial de festejos de sus primeras diez ediciones.

\section{El PROgRAma oficial de fESTEJOS}

La primera celebración de la Fiesta Nacional del Ternero y Día de la Yerra se realizó el 3 y 4 de mayo de 1969. Tras la sanción del decreto nacional que le dio entidad, se inició la convocatoria a diversas asambleas, con el fin de constituir una comisión que organizara los festejos. La misma estaba conformada por algunos de los participantes de la yerra en San Bernardo, más la participación del cura párroco, un representante de la Municipalidad y algunos integrantes vinculados actividades comerciales (Villanueva, 2014). Esta comisión 
será la encargada de desarrollar las primeras tres ediciones de la fiesta, y ya a partir de la cuarta edición, la Asociación Civil Fiesta Nacional del Ternero y Día de la Yerra será la encargada, hasta la actualidad, de llevar adelante los festejos.

Cada una de las instancias de esta celebración nos dice mucho sobre las intencionalidades que inspiraron a quienes la idearon y a quienes la celebraron.

En el programa oficial de la primera edición de la Fiesta Nacional del Ternero y Día de la Yerra se deja entrever la fuerte presencia de ese mundo rural que se está celebrando. Dicho documento está plagado de eventos que refieren a la actividad agropecuaria. La exposición de terneros, la demostración de la yerra, las jineteadas, el almuerzo criollo conforman los principales sucesos de la primera edición. Pero también se agregan otros, como la elección de la reina o el desfile oficial.

En el marco de la celebración aquí estudiada, la realización de cada uno de estos eventos estaba a cargo de subcomisiones dentro de la comisión organizadora, y, a partir de 1973, de la Asociación Civil Fiesta Nacional del Ternero y Día de la Yerra. Cada una de estas debía resolver cuestiones que atañían a la logística de la fiesta (Programa de la Primera Edición de la Fiesta Nacional del Ternero y Día de la Yerra, 1969. Archivo Asociación Civil Fiesta Nacional del Ternero y Día de la Yerra, Ayacucho).

El programa oficial de festejos de la primera fiesta se inició el sábado 3 de mayo con el izamiento de la bandera nacional por parte del intendente acompañado de una escolta de gauchos. Continuaba en las instalaciones de la Sociedad Rural y luego en la llamada Chacra Municipal. En la primera institución se inauguró oficialmente la fiesta y se procedió a la labor de los jurados de la Exposición de Terneros de Destete así como la de los de la Exposición, Industrial, Comercial y Artística. En la segunda, se llevó adelante la yerra: el rodeo de 150 vacas de cría. En el mediodía de ese mismo día se inició el Almuerzo Criollo, fogón especialmente destinado a las autoridades participantes e invitados especiales. Por otro lado, estaban las parrilladas para el público en general. Durante la tarde se procedió a las presentaciones de gauchos, carruajes y tropillas y los entrenamientos camperos, jineteadas.

La segunda jornada, el domingo 4 de mayo, el programa se inició con el arribo de las autoridades nacionales y provinciales y la recepción de las mismas por parte de los funcionarios municipales. Luego, los festejos oficiales se trasladaban al templo parroquial donde se llevaba adelante la misa oficial. El programa continuaba en la sede de la Sociedad Rural, donde se procedía a inaugurar la exposición y la venta de terneros de destete. Luego, era el momento del almuerzo criollo en honor a autoridades y expositores. En ese marco, el programa pautaba la entrega de los premios a los expositores y el inicio de la labor del jurado de las reinas. Por la tarde del domingo, en la zona céntrica de la ciudad se llevaría adelante el desfile oficial con la participación de las aspirantes a reina, gauchos, amazonas, tropillas y delegaciones. Luego de la elección de la reina, la fiesta concluía con la actuación de solistas y conjuntos folclóricos de jerarquía, la quema del monumento pirotécnico al ternero y la apertura de fogones populares en las calles de la ciudad (Programa de la Primera Edición de la Fiesta Nacional del Ternero y Día de la Yerra, 1969. Archivo Asociación Civil Fiesta Nacional del Ternero y Día de la Yerra, Ayacucho).

Estos eran los eventos presentes en el primer programa de festejos de la fiesta que aquí nos ocupa. La intención de este apartado no es hacer una descripción de cada uno de los programas a lo largo de la década estudiada, sino, en función de las características que asume su primera edición, dilucidar aquellos eventos que se transformaron y aquellos que tuvieron continuidad en el resto de las ediciones de la fiesta. ${ }^{6}$

\section{El tiempo festivo}

Una primera modificación que es posible observar a lo largo de la primera década de festejos refiere a la extensión del período de celebración, que oscila desde los 3 a los 7 días en las ediciones que sucedieron a la primera. En general, se distinguen, dentro de estos períodos festivos extendidos, dos momentos: uno, que se 
produce en los días hábiles, en los cuales se concentran actividades vinculadas a iniciativas de instituciones de arraigo urbano como las muestras comerciales, el adorno de vidrieras, los concursos fotográficos, de dibujo y literarios, las exposiciones de pinturas y los espectáculos musicales (folclóricos, de jazz o de tango). Este tipo de eventos empezó a aparecer en el programa de festejos a partir de la segunda celebración y adquirió mayor vigencia a medida que trascendió la década. En conjunto con ello, nuevas instituciones iniciaron su participación en la celebración: escuelas, clubes, agrupaciones y espacios culturales, peñas folclóricas, entre otras.

Un segundo momento tiene lugar los días sábado y domingo, cuando, al igual que en la primera celebración, se concentraron los espectáculos asociados a la tradición rural así como los eventos característicos de la primera edición. Por otra parte, en esos dos días es posible distinguir el arribo de las autoridades nacionales, provinciales y de otras localidades, así como el desarrollo de la misa oficial (Programas oficiales de la Fiesta Nacional del Ternero y Día de la Yerra, 1969- 1979. Archivo Asociación Civil Fiesta Nacional del Ternero y Día de la Yerra, Ayacucho).

Dentro de estas manifiestas continuidades, se perciben algunos cambios que, a medida que se desarrollan las ediciones de la celebración, se van arraigando y que, a nuestro entender, van modificando la celebración y el sentido de la misma.

\section{La elección de la reina}

Uno de los eventos característicos de este tipo de festividades fue la elección de la reina de la fiesta. En este sentido, el abordaje de Lobato, Damilakou y Tornay (2004) sobre las reinas del trabajo durante el peronismo arroja luz con respecto a este acontecimiento. Allí hacen un exhaustivo recorrido sobre las celebraciones del $1^{\circ}$ de Mayo y las características que asumió la elección de la reina durante esos festejos. Sostienen que

el ritual del 1 de mayo servía para exaltar la nación de los trabajadores, pero la elección de una reina del trabajo implica también una exhibición pública del cuerpo de una mujer que se aleja de las imágenes más frecuentemente conocidas sobre las mujeres que trabajan (Lobato, Damilakou y Tornay, 2004, p. 234).

A su entender, las elecciones de las reinas implicaban una largo proceso, al final del cual la mujer más bella era elegida representante provincial o regional del trabajo y, finalmente, en la ceremonia del $1^{\circ}$ de mayo, reina nacional (Lobato, Damilakou y Tornay, 2004).

La misma modalidad se adoptó en las celebraciones festivas vinculadas a la producción local. La elección de la reina constituía el punto de encuentro entre esas tradiciones rurales que se estaban reivindicando y las vicisitudes de la sociedad contemporánea. La fiesta consagraba y coronaba a la más bella: "la elige para representar al evento, al Partido, y a una honrosa actividad, a la mujer rural, símbolo permanente de la belleza y exponente de una formación espiritual y educativa que, cada día, adquiere mayor significación" (Revista de la tercera edición de la Fiesta Nacional del Ternero y Día de la Yerra, Ayacucho, 1971).

En un principio, al menos según consta en el programa oficial, las aspirantes a reina nacional del ternero y día de la yerra solo hacían su presentación durante el desfile oficial. A medida que se sucedieron las distintas ediciones de la fiesta, es posible observar cómo su aparición empezó a ser más frecuente durante los distintos momentos de la celebración. El Almuerzo Criollo, el espectáculo folclórico en la Chacra Municipal o el show musical en el Estadio Municipal, el cóctel en el Club Social, el baile popular en las calles, pasaron a ser los otros eventos en los cuales hacían su presentación las aspirantes a reina de la Fiesta Nacional del Ternero y Día de la Yerra. Esta situación quedó detallada en el programa de festejos de cada una de las ediciones (Programas oficiales de la Fiesta Nacional del Ternero y Día de la Yerra, 1969- 1979. Archivo Asociación Civil Fiesta Nacional del Ternero y Día de la Yerra, Ayacucho). Podemos afirmar que la presentación de las aspirantes a reina pasó a ser uno de los eventos centrales dentro de la celebración, ya que su mención 
dentro del programa se hizo más recurrente y se fue consolidando como un atractivo para los espectadores que asistían a los distintos espectáculos.

\section{La presencia de funcionarios públicos}

Otro de los acontecimientos en los que repara el programa oficial, a partir de la segunda celebración, refiere a la inauguración de obras públicas (tales como nuevas rutas o dependencias del Estado) en el marco de la celebración. En ese contexto, las reuniones oficiales entre las autoridades pasaron a formar parte de tiempo festivo. Un ejemplo de ello es la mención a la inauguración de la ruta provincial 74 (tramo Las Armas-Ayacucho) con la presencia del gobernador de la provincia de Buenos Aires, el ministro de Asuntos Agrarios y el intendente en la cuarta edición de la fiesta (Programa Fiesta Nacional del Ternero y Día de la Yerra, 1973. Archivo de la Asociación Civil Fiesta Nacional del Ternero y Día de la Yerra, Ayacucho). La presencia y el discurso oficial de miembros del gobierno nacional, provincial y local quedó registrada en los distintos programas de festejos. La asistencia en el período estudiado de los gobernadores de facto, como Francisco Imaz, Saturnino Llorente, Ibérico Saint Jean, de los ministros de Asuntos Agrarios de la provincia, Rogelio Gallareta, Alfredo Orfanó, Pedro Augusto Goin, o del secretario de Agricultura y Ganadería de la Nación, Rafael García Mata, entre otros, marca la relevancia que este tipo de festividades fue adquiriendo para dichos gobiernos. Su participación en la fiesta no solo los acercó a los habitantes de estas sociedades del interior, sino que les sirvió como instrumento de difusión y propaganda de las políticas llevadas adelante por el gobierno del cual formaban parte. Es posible, a partir de un recorrido por la prensa local y nacional, reconstruir parte de los discursos que dichas autoridades desarrollaban durante su presencia en la fiesta.

De hecho, la aceptación que la realización de la primera fiesta tuvo en la comunidad, de alguna manera le permitió al comisionado local, Guillermo Schoo Lastra, ${ }^{8}$ legitimarse frente una comuna que en su mayoría le era extraña, y ante un sector opositor (la UCR), que a lo largo de dieciocho años había sido la única fuerza mayoritaria gobernante a nivel local (Villanueva, 2014).

\section{La Mesa Redonda}

A la participación en la fiesta de funcionarios de gobierno al frente de los ministerios o secretarías encargadas de elaborar políticas hacia el sector agropecuario, también se le suma la participación de los principales referentes de las organizaciones del agro. Es así que el tiempo festivo se convirtió en un momento propicio para elevar los reclamos al gobierno provincial y nacional sobre aquellas políticas con las cuales no se estaban de acuerdo. Un ejemplo de ello es cuando, en 1971, la celebración debió ser postergada de las fechas habituales en las cuales se había desarrollado anteriormente, "por motivo de solidaridad con las sociedades rurales (CARBAP) ante la imposición de la veda de carne roja” (Nueva Era, 9 de junio de 1971, Tandil). Ese año, durante los festejos, la Sociedad Rural de Ayacucho difundió un petitorio destinado a las autoridades nacionales que se hicieron presentes en la celebración, con "los requerimientos mínimos e inmediatos que los productores de la región consideran que deben cumplirse en defensa de la ganadería argentina" (La Verdad, 14 de julio de 1971, Ayacucho). Entre ellos pedían la suspensión de la Ley Federal de Carnes, el control por parte de provincia de las normas económicas dictadas por el gobierno nacional en cuanto significan una expansión del sector público, y por último el descenso de las tasas impositivas hacia el sector.

En la edición de 1972, el ministro de Asuntos Agrarios, Alfredo Orfanó, afirmaba, sentando la posición gubernamental con respecto al sector, que

La ganadería reclama praderas artificiales, alimentación racional, rigurosa sanidad, nuevos tipos y razas, racionalización empresaria y adecuados mecanismos de comercialización. Consciente de este cambio moderno, el Ministerio de Asuntos Agrarios concurre a él, mediante programas destinados a mejorar la receptibilidad de los terrenos y renovar los planteles 
reproductores y modernizar los métodos y técnicas sobre manejo y defensa del ganado (...) de tal manera el campo de ayer cederá paso a un campo, al de hoy, al de mañana, ágil, racional, moderno y ello, sobre la base de un mismo espíritu, de los mismos valores que han fundado su historia y que tienen plena reafirmación en esta brillante fiesta ( La Verdad, 2 de mayo de 1972, Ayacucho).

En la edición de 1974, el ministro de Asuntos Agrarios de la provincia de Buenos Aires hizo un recorrido por las principales políticas vinculadas al sector, las cuales giraban en torno a la sanidad vegetal y animal y el desarrollo de la colonización (La Verdad, 6 de mayo de 1974).

Por el lado de los funcionarios de gobierno, la fiesta era un instrumento eficaz para difundir las intenciones que perseguían las políticas públicas con respecto al sector agropecuario. Por parte de las entidades representantes del sector, la misma era un espacio en el cual podían acercar sus vicisitudes y desacuerdos con respecto a la aplicación de dichas políticas.

Tan recurrente se hicieron estas manifestaciones que, a partir de mediados de la década de setenta, se organizó un congreso nacional de ganadería, que luego se tradujo en una mesa redonda. En esta, los productores ganaderos, las autoridades respectivas (nacionales, provinciales y locales) y los sectores del trabajo se reunían con el fin de debatir y delinear políticas acordes para el sector. La Mesa Redonda fue otro de los eventos que dieron cuenta de un proceso de resignificación de la fiesta por parte de algunos de sus organizadores, pero también de sus participantes. Articulaban el encuentro, en el marco de la celebración, entre especialistas sobre la actividad rural, la palabra de los funcionarios públicos y sus políticas hacia el sector, y la postura de los productores rurales afectados por las mismas. La primera Mesa Redonda, organizada por la Sociedad Rural de Ayacucho, se desarrolló el día 2 de mayo, en el marco de la séptima fiesta (1975). El título de la misma fue "La ganadería argentina, evolución y perspectiva". En ella se encontraron el presidente de la Junta Nacional de Carnes, el presidente de CARBAP, el ex subsecretario de Agricultura y Ganadería, Tomás J. Anchorena, el presidente de la Asociación de Industrias Argentinas de Carnes, profesionales del área y referentes de instituciones vinculadas al agro (La Verdad, 19 de abril de 1975, Ayacucho. Los temas tratados durante la década aquí estudiada estuvieron vinculados a las políticas hacia el sector, la comercialización y la recría del ternero.

Las políticas agropecuarias eran motivo de innumerables debates, que interpelaban principalmente a los sectores vinculados al mundo rural, particularmente a productores agropecuarios, pero también a los funcionarios públicos y a la población en general (fundamentalmente a la establecida en aquellas localidades vinculadas a la actividad). El contexto festivo constituyó un ámbito propicio para manifestar públicamente distintas percepciones sobre la situación del agro, sobre el rol del Estado frente a las demandas del mismo, así como también se entrevén en él diferentes proyecciones sobre el campo y su lugar en un contexto de transformación. Un ejemplo de ello lo constituye la participación del ya citado, Jorge Aguado, entonces presidente de CARBAP, quien durante el desarrollo de la primera Mesa Redonda, en disidencia con las políticas gubernamentales sostuvo que,

El productor agropecuario argentino es el único en el mundo libre que no percibe el valor real de su producto en el mercado internacional (...). La situación actual sin política agropecuaria marca un estado de distorsión grave en la que el productor no participa de las decisiones (La Verdad, 5 de mayo de 1975, Ayacucho).

No obstante, a pesar de la creación de este espacio, los reclamos siguieron manifestándose en otros eventos de la celebración.

\section{Los espectáculos folclóricos}

Otro de los eventos que adquieren mayor relevancia en el Programa de Festejos a medida que se desarrollaron las distintas ediciones de la fiesta son los bailes populares en las calles céntricas de la ciudad, los shows musicales y las peñas folclóricas. Mientras que en la primera fiesta el programa oficial hacía referencia a espectáculos folclóricos dentro de la Chacra Municipal o en los fogones, a partir de la segunda 
fiesta empezaron a aparecer otros espacios, además de los mencionados, donde se realizaban este tipo de espectáculos.

El lugar otorgado a la música folclórica fue ganando espacio dentro del programa oficial de festejos hasta convertirse en un suceso con entidad propia. Los bailes populares en las calles y los clubes ampliaban el abanico de estilos musicales que podían encontrarse en el desarrollo de la fiesta, aunque en el programa solo se hace referencia al jazz, tango y folclore. Este último género musical aparece constantemente. Los bailes estaban destinados al común de la gente. Paralelamente, en el club social de la ciudad se llevaba adelante el cóctel de agasajo a autoridades, invitados especiales y periodistas.

A partir de 1974, empezó a adquirir presencia lo que se denominó el Certamen Promocional del Folclore. Como ya mencionamos, desde la primera fiesta el folclore ocupó un lugar central en el marco de los espectáculos de destreza criolla llevados adelante en la Chacra Municipal los días sábados. En la edición de 1972, se agregó otro lugar en el cual se desarrollaron espectáculos folclóricos: el Estadio Municipal. En el año 1973 se añadió al festejo el desarrollo de un concurso folclórico a cargo de aficionados de la zona (Programa de la Fiesta Nacional del Ternero y Día de la Yerra, 1973. Archivo de la Asociación Civil Fiesta Nacional del Ternero y Día de la Yerra, Ayacucho). En la siguiente fiesta se desarrolló una gran peña folclórica. En la fiesta de 1975, se retoma el concurso de folclore, esta vez denominado Segundo Certamen Promocional del Folclore, que mantendrá continuidad en este período. La vigencia del folclore dentro del programa de festejos sería impreciso interpretarla si no consideráramos el boom del folclore de inicios de la década del sesenta, que dio un nuevo marco al contexto en el cual proliferaron estas fiestas. "La música popular fue una de las formas de expresión más importantes de la década y el llamado boomfolclórico tuvo lugar aquí" (Cavallo, 2013, p. 10). Este boom se caracterizó por la expansión de eventos cuyo eje central lo constituía la difusión del estilo folclórico y todo aquello que refiera a ella. La emergencia de peñas folclóricas, programas de televisión destinados a la difusión del género, festivales folclóricos exclusivos como el Festival de Cosquín o la difusión de revistas adquirieron relevancia hacia principios de esta década (Cavallo, 2013). Fue una manifestación cultural que no reconoció clases sociales. De alguna manera, la expansión de los espectáculos folclóricos dentro del marco de la fiesta da cuenta de los consumos predilectos del público asistente en ese momento, no obstante, en el devenir de la década del setenta esta situación irá modificándose, sobre todo hacia fines de la misma.

Muchos de los artistas que participaron de la fiesta formaban parte de las nuevas promesas del estilo folclórico, otros habían iniciado su exitosa carrera en la década del sesenta, al calor del folclore comercial y de denuncia que tuvo su expresión más significativa en el Movimiento Nuevo Cancionero, oponiéndose a las vicisitudes del folclore tradicional. Ya hacia la década del setenta estas expresiones debían lidiar con el avance de otros estilos musicales que iban adentrándose en el gusto popular, particularmente la proliferación de lo que denominaban música extranjera.

Aparecieron en la década de los setenta nuevos representantes del género, pero con menor compromiso político y social que el que había caracterizado al período anterior. Durante los primeros cinco años de celebración, la presencia de Jorge Cafrune, José Larralde, Los Quilla Huasi, Horacio Guaraní fue central en el espectáculo folclórico de la fiesta. A partir de 1975, empiezan a adquirir mayor vigencia los artistas regionales, aunque también los ganadores del Festival de Cosquín participaban de la fiesta. Cada vez la oferta folclórica se hacía más amplia y heterogénea: Ariel Ramírez, Eduardo Falú, Los Bombos Tehuelches, Luis Landriscina, Los Tucu-tucu, entre otros, dan cuenta de esta situación.

Es posible afirmar que la fiesta daba lugar a un eclecticismo ideológico importante, si consideramos que muchos de estos artistas y sus repertorios musicales fueron prohibidos durante el gobierno de facto e inclusive ya desde 1975, como era el caso de Horacio Guaraní (Cavallo, 2013).

Finalmente, la quema del monumento pirotécnico al ternero -que durante las primeras ediciones de la fiesta ocupó un lugar central dentro de la celebración ya que marcaba su fin-dejó de realizarse. La idea de la 
realización del mismo fue tomada de los festejos de las fallas valencianas, que año tras año se recreaban en la ciudad de Mar del Plata (Villanueva, 2014).

\section{Algunas consideraciones}

En el contexto de reconfiguración de la estructura agraria, pero también de la articulación del tejido social rural, adquieren importancia por su expansión territorial, las fiestas orientadas a celebrar alguna actividad económica o prácticas vinculadas al quehacer rural. Como sostienen Eduardo Míguez y Estela Spinelli (2014), "la presencia de estas formas culturales, acotadas pero vivas, pone de manifiesto un rasgo de la globalización. A la vez que universaliza el escenario cultural, crea infinidad de espacios donde grupos de interés se nuclean en torno a sus propias aficiones" (p. 84).

Estas fiestas se erigieron como baluarte de la expresión de identidades locales; al menos así fueron entendidas por quienes las dotaron de significación en sus inicios. Distintas instituciones fueron incorporándose a través del tiempo en la organización de los eventos y modelándolos, por lo que reunieron nuevos intereses y significados.

En la provincia de Buenos Aires, la institucionalización de estas celebraciones se produce hacia fines de la década del sesenta y continúa en la década siguiente. Este surgimiento se dio en un momento en el cual, no solo el sector agropecuario estaba atravesando significativas transformaciones estructurales (cambios en las formas de producir, incorporación de nuevas técnicas de producción, cambios en la producción), sino que también las propias sociedades del interior rural bonaerense estaban siendo signadas por importantes cambios sociales y culturales, marcados fundamentalmente por el movimiento de población del mundo rural hacia las ciudades cabeceras de partido, y la migración de población de estas hacia grandes ciudades como Mar del Plata o los municipios del Gran Buenos Aires. Esto trajo aparejado importantes cambios en las prácticas culturales.

En el recorrido por el programa oficial de festejos de la primera década de celebración de la Fiesta Nacional del Ternero y Día de la Yerra encontramos algunos elementos que nos permiten aproximarnos a las transformaciones que sufrió la sociedad que celebraba. En principio, es pertinente mencionar la mayor gravitación que empezaron a tener dentro de la celebración aquellas instituciones del ámbito de sociabilidad urbano. La escuela, la biblioteca, los clubes, los comercios, son algunas de las instituciones que empezaron a gravitar en la organización de eventos artísticos dentro del marco festivo. Esta injerencia se traduce también en la procedencia de las personas que más adelante formarían parte de las comisiones organizadoras y posteriormente de la Asociación Civil. Es decir que, a las intenciones iniciales que perseguían quienes organizaron las primeras celebraciones (difundir las tradiciones rurales) se agregaban los intereses de quienes estaban más vinculados a las actividades de origen urbano.

También a través de este análisis podemos señalar algunos de los cambios en los consumos y prácticas culturales que se producen en este período de tiempo y que podemos vislumbrar en el programa oficial. Si bien el boom del folclore ha sido situado hacia principios de la década del sesenta, es posible visualizar que en la fiesta aquí estudiada, el consumo de la música folclórica continuó vigente a lo largo de la década del setenta, lo que dio lugar, dentro de la celebración, a un evento propio, como fue el Certamen de Música Folclórica. Sin embargo, también empiezan a aparecer dentro del programa momentos destinados al jazz e inclusive al tango. ¿A qué se debe la incorporación de estos estilos musicales que, si bien no adquieren la presencia que sí tiene la música folclórica, empiezan a ser mencionados dentro de la programación oficial? Es posible que una indagación de las décadas posteriores nos permita dilucidar si estos eventos perduraron en el tiempo o fueron incorporados para ampliar la oferta de espectáculos durante la celebración y observar así los gustos del público.

Asociada a las prácticas culturales, la recurrencia de las aspirantes a reina en los distintos eventos descriptos en el programa da cuenta de la mayor relevancia que adquiere la presencia femenina (y las representaciones y proyecciones sobre ella) dentro del evento. 
También la realización de una mesa redonda referida a la problemática agropecuaria, en la que participaban representantes de las entidades rurales, expertos y funcionarios del gobierno, vino a canalizar una demanda que se había ido constituyendo a lo largo de las primeras ediciones. La presencia de funcionarios públicos y de referentes del agro ocasionaba el momento propicio para que ambas partes dieran cuenta de sus miradas sobre la política agropecuaria y la situación en general del agro. Muchas veces las disputas que se observaban a nivel nacional repercutían en los festejos. Así sucedió con la veda impuesta a la comercialización de la carne a principios de la década del setenta.

Si bien la fiesta tenía como fin, desde sus inicios, celebrar y homenajear elementos vinculados a la actividad rural característica del partido de Ayacucho, es la interacción entre los intereses de los distintos sectores de la sociedad la que termina por configurar dicha celebración a través de sus distintas ediciones.

¿Son las fiestas un espejo de la sociedad? Es decir, ¿nos brinda la fiesta una imagen exacta de lo que caracteriza a las sociedades que celebran o meramente algunos destellos de la misma? Desde nuestra perspectiva, y en coincidencia con la mirada de Ariño Villarroya (1992), entendemos que la fiesta adquiere la dinámica propia de una sociedad que está en constante cambio. En el tiempo festivo se entrecruzan quienes buscan conservar ciertas tradiciones a través de su reivindicación, así como actores portadores y demandantes de nuevas prácticas y consumos culturales que le otorgan otros significados a la celebración.

Esta primera aproximación, que realizamos a partir del análisis del programa oficial de los primeros diez años de celebración, nos permitió acercarnos a conocer la dinámica que fue adquiriendo la fiesta, $\mathrm{y}$, a través de ella, adentrarnos en los intereses y actores que la fueron significando. Entendemos que, mediante un recorrido por las transformaciones que se manifiestan en la celebración en un período más extenso podremos aproximarnos al conocimiento de las tensiones que atraviesan a esa sociedad, a su forma de entender y relacionarse con su pasado y con su presente, a las instituciones que son legitimadas como pilares de la misma, a los cambios en las prácticas culturales, las formas en que los distintos sectores sociales se representan y se conciben dentro de la comunidad.

\section{REFERENCIAS}

Ariño Villarroya, A. (1992). La ciudad ritual. La fiesta de las fallas. Barcelona: Anthropos.

Aronskind, R. (2007). El país del desarrollo posible. En J. Daniel (Comp.), Nueva Historia Argentina, Violencia, proscripción y autoritarismo (1955-1976). Buenos Aires: Sudamericana. Pp. 63-116

Balsa, J. (2006). El desvanecimiento del mundo chacarero, Transformaciones sociales en la agricultura bonaerense 1937-1988. Buenos Aires: Universidad Nacional de Quilmes.

Balsa, J. (2014). Estructura y política agraria. En O. Barreneche (Dir.), Historia de la provincia de Buenos Aires, Tomo 5: Del primer peronismo a la crisis del 2001. Buenos Aires: UNIPE Editorial Universitaria EDHASA. Pp. 147-177.

Barsky O., y Gelman J. (2001). Historia del agro argentino. Desde la conquista hasta fines del siglo XX. Buenos Aires: Grijalbo Mondadori.

Cavallo, M. (2013). La Revista Folklore: boom folklórico, nacionalismo y dictadura (1961-1981) (Tesis de Licenciatura), Universidad Torcuato Di Tella, Buenos Aires, Argentina https://repositorio.utdt.edu/bitstream/handle/utdt/ 1539/LHIS_2013_Cavallo.pdf?sequence $=1 \&$ isAllowed $=y$

Chamosa, O. (2012). Breve historia del folclore argentino, 1920-1970: identidad, politica y nación. Buenos Aires: Edhasa. Chartier, R. (2005). El mundo como representación. Estudios sobre historia cultural. Barcelona: Gedisa Editorial.

Garavaglia, J. C. (2007). Construir el estado, inventar la nación. El Río de la Plata, siglos XVIII-XIX. Buenos Aires: Prometeo Libros.

Lobato, M., Damilaku, M., y Tomay, L. (2004). Belleza femenina, estética e ideología. Las reinas del trabajo durante el peronismo. Anuario de Estudios Americanos, 61(1), 33-277. 
Míguez, E., y Spinelli, E. (2014). La sociedad bonaerense, 1943-2001. En O. Barreneche (Dir.), Historia de la provincia de Buenos Aires, Tomo 5: Del primer peronismo a la crisis del 2001. 413-438. Buenos Aires: UNIPE Editorial Universitaria EDHASA.

Munilla lacasa, M. L. (2013). Celebrar y gobernar. Un estudio de las fiestas civicas en Buenos Aires, 1810-1835. Buenos Aires: Miño y Dávila.

Navarro, A. (2011). La actividad simbólica del pasado a través de actividades performativas: los festivales gauchos y las milongas tangueras. En S. Figueroa-Dreher, Dreher y H. Soeffner (comp.), Construcciones de identidad y simbolismo colectivo en Argentina. Buenos Aires: Prometeo.

Ortemberg, P. (2009). La entrada de José de San Martín en Lima y la proclamación del 28 de julio: la negociación simbólica de la transición. Histórica, 33(2), 65-108.

Ozouf, M. (2020). La Fiesta revolucionario, 1789-1799. Zaragoza: Universidad Nacional de Zaragoza. Prensas.

Ratier, H. (2004). Poblados bonaerenses. Vida y milagros. Buenos Aires: La colmena.

Salvatore, R. (1996). Fiestas federales: representaciones de la república en el Buenos Aires rosista. Entrepasados, VI(11) 45-68.

Villanueva, S. (2014). Politica y comunidad en el sudeste de la Provincia de Buenos Aires: La Fiesta Nacional del Ternero y Día de la Yerra (Ayacucho, 1940-1969) (Tesis de licenciatura). UNICEN, Tandil, Argentina.

\section{Notas}

1 Discurso pronunciado por el comisionado municipal con motivo de la primera edición de la Fiesta Nacional del Ternero y Día de la Yerra, Ayacucho, Mayo de 1969. Archivo de la Asociación Civil Fiesta Nacional del Ternero y Día de la Yerra, Ayacucho.

2 Decreto Nacional 2.721, Buenos Aires, 17 de mayo de 1968. Archivo de la Asociación Civil Fiesta Nacional del Ternero y Día de la Yerra, Ayacucho.

3 Se trabajarán los programas oficiales de las primeras diez ediciones de la fiesta. Los mismos se encuentran en el Archivo de la Asociación Civil Fiesta Nacional del Ternero y Día de la Yerra. La edición de 1976 no se realizó.

4 Según el Censo Nacional de Población entre 1960 y 1980, la población rural del partido pasa de 8.568 a 6.414 habitantes.

5 La estancia San Bernardo ocupaba aproximadamente más de 2000 hectáreas y era propiedad de los hermanos Alejandro y Ricardo Araoz, ambos productores ganaderos. Hacia ese año contaba con una importante presencia de ganado vacuno (Villanueva, 2014).

6 Es necesario aclarar que en el año 1976 la fiesta no se realizó.

7 El diario La Verdad de Ayacucho realizaba coberturas especiales de los festejos desde su primera edición. También y particularmente en las primeras ediciones, los diarios de tirada nacional como La Nación y Clarín realizaban una cobertura del evento.

8 El nuevo comisionado municipal era oriundo de Capital Federal y había sido nombrado en su cargo por el gobernador de facto de la provincia de Buenos Aires, el Gral. Francisco Imaz. Tras la renuncia a nivel local del intendente representante del Unión Cívica Radical del Pueblo, Alfredo A. Cordonnier, y después de un breve gobierno del Teniente Juan Carlos Donovan, Schoo Lastra asume como máxima autoridad local (Villanueva, 2014). 